Original Research Paper

\title{
Keragaman Sumberdaya Ikan Non Target Perikanan Rajungan di Pesisir Lampung Timur
}

\author{
Iya Purnama Sari ${ }^{1}$, Zairion ${ }^{1,2,3} *$, Yusli Wardiatno ${ }^{2,3,4}$ \\ ${ }^{1}$ Program Studi Pengelolaan Sumberdaya Pesisir dan Lautan, Sekolah Pascasarjana, Institut Pertanian Bogor, Kampus IPB Dramaga, \\ Bogor 16680. \\ ${ }^{2}$ Departemen Manajemen Sumberdaya Perairan, Fakultas Perikanan dan Ilmu Kelautan, Institut Pertanian Bogor, Kampus IPB \\ Dramaga, Bogor 16680. \\ ${ }^{3}$ Pusat Kajian Sumberdaya Pesisir dan Lautan, Institut Pertanian Bogor, Kampus IPB Baranangsiang, Bogor 16143 \\ ${ }^{4}$ Pusat Penelitian Lingkungan Hidup IPB, Kampus IPB Darmaga, Bogor 16680
}

\section{Article history}

Received: 26 November 2018

Revised: 10 Januari 2019

Accepted: 24 Januari 2019

Published: 8 Februari 2019

*Corresponding Author:

Zairion,

Pusat Kajian Sumberdaya Pesisir dan Lautan, Institut Pertanian Bogor, Kampus IPB Baranangsiang, Bogor 16143 Email:

zairion.zai@gmail.com

\begin{abstract}
Abstrak - Penelitian ini dilakukan dengan tujuan untuk mengidentifikasi keragaman dan komposisi ikan non-target perikanan rajungan dengan alat tangkap jaring insang dasar. Sampel dikumpulkan dari bulan Juni hingga Oktober 2017 di Labuhan Maringgai dan Kuala Penet, Pesisir LampungTimur. Hasil penelitian menunjukkan bahwa21 species ikan non-target yang diidentifikasi di Labuhan Maringgai dan Kuala Penet sertamemiliki kesamaan spesies. Di Labuhan Maringgai, 15 spesies (11,40\%) ikan non-target tergolongretained speciesyang dimanfaatkan untuk konsumsi atau dijual dan enam spesies $(0,89 \%)$ termasuk discarded speciesataudibuang. Sementara di Kuala Penet, 14 spesies $(8,76 \%)$ tergolongretained dan tujuh spesies $(1,28 \%)$ discarded species. Hasil penelitian ini membantu untuk mengklarifikasi keragaman ikan non-target yang ditemukan dari perikanan jaring insang dasar di Pesisir Lampung Timur.
\end{abstract}

Kata kunci : jaring insang dasar, ikan, perikanan rajungan, species yang dimanfaatkan, spesies yang dibuang

Abstract- The study was conducted with the aim to identifying non-target fish diversity and composition from blue swimming crab set gill-net fishery. Samples were collected from June to October 2017 at Labuhan Maringgai and Kuala Penet, Coastalarea of East Lampung. The results showed that 21 nontarget fish species obtainedfromLabuhan Maringgai and Kuala Penet areas and it was similar in terms ofspecies diversity. In Labuhan Maringgai area, 15 species (11.40\%) of non-target fish were retained either as fisher own consumption or marketing and six species (0.89\%) were discarded. While in Kuala Penet area, 14 species $(8.76 \%)$ were retained and seven species $(1.28 \%)$ were discarded. The result of this study helps to clarify diversity of non-target fish found from bottom set gill-net fishery in coastalarea of East Lampung.

Keywords : swimming crab fishery, bottom set gill-net, discarded species, fish, retained species

\section{Pendahuluan}

Pesisir Lampung Timur merupakan perairan pantai dengan tipe terbuka, terdapat pada bagian barat Laut Jawa. Wilayah pesisir ini digunakan untuk berbagai kegiatan diantaranya yaitu kegiatan perikanan tangkap, pelabuhan, maupun pemukiman.
Salah satu kegiatan perikanan tangkap terbesar di wilayah ini yaitu penangkapan rajungan. Aktivitas ini mendaratkan rajungan di beberapa tempat diantaranya di Labuhan Maringgai dan Kuala Penet.

Pesisir Lampung Timur merupakan salah satu perairan pesisir yang potensial sebagai daerah penangkapan rajungan di Indonesia. Produksi 
rajungan di daerah ini cenderung meningkat dalam kurun waktu 10 tahun terakhir, namun terjadi penurunan produktivitas penangkapannya (Wardiatno dan Zairion, 2011). Tahun 2017 produksi rajungan relatif mengalami penurunan dari tahun-tahun sebelumnya. Penangkapan rajungan umumnya diusahakan dalam perikanan skala kecil dengan alat tangkap yang dominan adalah jaring insang dasar (bottom set gill-net) (Zairion et al., 2014).

Aktivitas penangkapan rajungan sebagai spesies target menghasilkan spesies non-target (nontarget species, NTS) diantaranya ikan, udang, kerang-kerangan dan bintang laut. European Commission (EC) paper (European Commission, 2002) mendefinisikan spesies non-target sebagai spesies komersial yang tertangkap lalu dibawa ke kapal dan spesies yang dibuang kembali ke laut sebagai spesies non-komersial. Aktivitas penangkapan rajungan dengan menggunakan alat tangkap jaring insang dasar menyebabkan banyaknya spesies non-target yang terperangkap didalamnya.

Spesies non-target yang tertangkap dapat dikelompokan menjadi retained species dan discarded species. Spesies yang bisa dimanfaatkan (retained species) dan spesies yang tidak dapat dimanfaatkan karena tidak memiliki nilai ekonomis sehingga dibuang kembali ke perairan (discarded species), yang mana spesies inilah yang berpotensi menjadi limbah di perairanatau di sekitar lokasi pendaratan.

Penelitian yang pernah dilakukan oleh Zairion (2015), didalamnya terdapat bagian yang mengkaji tentang spesies non-target pada perikananrajunganmenggunakanalat tangkap jaring insang dasar di Lampung Timur. Hasil penelitian tersebut menunjukkan tidak adanyaperbedaan proporsi jumlah individu rajungan terhadap spesies non-target menurut musim, namun proporsi bobotnya berbeda. Namun penelitian tersebut belum menganalisis dampak atau pengaruh daerah penangkapan (fishing ground) yang berbeda terhadap kelimpahan spesies non-target khususnya spesies ikan. Hal ini menjadi dasar perlunya kajian mengenai komposisi sumberdaya ikan spesies nontarget pada daerahpenangkapan yang berbeda sehingga dapat dijadikan informasi ilmiah dasar terkait keragaman sumberdaya ikan non-target pada perikanan rajungan di Pesisir Lampung Timur.

\section{Bahan dan Metode}

Penelitian dilakukan di lokasi pendaratan rajungan yaitu Labuhan Maringgai dan Kuala Penet, dengan daerah penangkapan (fishing ground) masing-masing. Rajungan dan sampel ikan nontarget dikumpulkan setiap bulan dari bulan Juni hingga Oktober 2017. Sumberdaya ikan non-target dan rajungan dikumpulkan dari kapal yang dioperasikan oleh nelayan dengan metode sampling acak (random sampling). Spesies non-target dipisahkan dari jaring, lalu dihitung jumlah dan ditimbang bobot setiap spesiesnya. Kegiatan ini dilakukan pada masing-masing lokasi pendaratan pukul 06.00-11.00 WIB (disesuaikan dengan waktu pendaratan oleh nelayan). Panjang total jaring yang digunakan nelayan pada kedua lokasi bervariasi antara 1,8-3,6 km, dengan tinggi jaring antara 70-90 cm. Ukuran mata jaring (mesh size) yang digunakan nelayan umumnya berkisar antara 3,0-4,0 inci dan didominasi oleh ukuran 3,0-3,5 inci.

Sumberdaya ikan spesies non-target yang diamati di lapangan difoto dengan menggunakan kamera digital, dan beberapa spesies ikan non-target diawetkan dengan alkohol 96\% lalu dibawa ke laboratorium untuk diidentifikasi. Selanjutnya dihitung persentase proporsi bobot sumberdaya ikan non-target terhadap rajungan yang dianalisis dari total lima bulan. Kemudian ikan non-target diklasifikasikan kedalam dua kelompok yaitu retained species yang dilambangkan dengan $(\mathrm{R})$ dan discarded species $(\mathrm{D})$, berdasarkan presepsi nelyan lokal (Alverson et al., 1994). 


\section{Hasil dan Pembahasan}

Hasil penelitian menunjukkan bahwa perbandingan rajungan $(P$. pelagicus) dan sumberdaya ikan spesies non-target pada dua lokasi pendaratan tidak sama, yang mana di Labuhan Maringgai menunjukkan proporsi bobotikan nontarget sedikit lebih tinggi dibandingkan Kuala Penet (Tabel 1). Spesies yang diamati di Labuhan Maringgai dan Kuala Penet tidak jauh berbeda.Di Labuhan Maringgai, terdapat 15 spesies $(11,40 \%)$ ikan non-target yang termasuk retained species dan enam spesies $(0,89 \%)$ termasuk discarded species, sedangkan di Kuala Penet, terdapat14 spesies $(8,76 \%)$ termasuk retained species dan tujuh spesies $(1,28 \%)$ termasuk discarded species.

Total proporsi bobot ikan non-target terhadap target tangkapan dari masing-masing lokasi yaitu 12,29\% di Labuhan Maringgai dan $10,04 \%$ di Kuala Penet. Hasil yang diperoleh ini jauh lebih rendah daripada keragaman spesies nontarget pada perikanan udang menggunakan alat tangkap trammel net, yang mana $40,5 \%$ adalah spesies non-target (Iskandar, 2010). Keragaman spesies non-target yang hampir mirip ditemukan perikanan udang menggunakan alat tangkap trap, yakni16,8\% (Favaro et al., 2009) dan 15\% pada perikanan rajungan atau blue swimming crab fishery (Zairion, 2015).

Tabel 1. Proporsi bobot spesies non-target ikan terhadap rajungan

\begin{tabular}{lllll}
\hline \multirow{2}{*}{ Lokasi } & \multicolumn{4}{l}{ Proporsi bobot $(\%)$} \\
\cline { 2 - 5 } & $\begin{array}{l}\text { Spesies } \\
\text { target }\end{array}$ & \multicolumn{4}{l}{ Spesies non-target ikan } \\
\hline & Rajungan & $\mathrm{R}$ & $\mathrm{D}$ & Total \\
\hline Labuan & 87,71 & 11,40 & 0,89 & 12,29 \\
Maringgai & 89,96 & 8,76 & 1,28 & 10,04 \\
Kuala Penet & & &
\end{tabular}

Spesies non-target yang tertangkap oleh nelayan lokal ini termasuk kedalam kategori normal bycatch dan cryptic bycatch. Normal bycatch artinya spesies non-target yang terperangkap pada jaring insang dalam keadaan hidup atau mati selama proses penangkapan dan cryptic bycatch artinya spesies non-target yang terjebak dalam alat tangkap, dan mati setelah mencoba melepaskan diri dari lilitanjaring (Leland et al., 2013; Reeves et al,. 2013).

Komposisi sumberdaya ikan non-target dari masing-masing lokasi dapat dilihat pada Tabel 2. Hasil yang diperoleh menunjukkan keragaman spesies organismelaut yang berbeda tertangkap pada dua lokasi pengamatan, khususnya ikan. Hal ini dapat dipengaruhi oleh kondisi musim atau habitat dan wilayah geografis, yang memiliki dampak potensial pada komposisi spesies dan struktur komunitas (Fazrul et al., 2015).

Penggunaan jaring insang dasar sebagai alat tangkap rajungan pada penelitian ini, masih berdampak terhadap tingginya spesies non-target yang tertangkap. Penggunaan alat tangkap ini juga dapat berdampak buruk terhadap spesies non-target, seperti menyebabkan luka dan kematian (Kelleher, 2005). Tingginya spesies non-target yang tertangkap dan terbuang telah menjadi isu internasional karena adanya pedoman untuk mengelola dan mengurangi spesies non-target yang terbuang menjadi limbah (FAO, 2014). Hal ini menjadi isu terhadap kerusakan ekosistem dan kelansungan hidup biota laut (Read, 2013). Masalah kerusakan ekosistem dan kelangsungan hidup biota laut adalah akibat penggunaan alat tangkap yang tidak selektif, sehingga menghasilkan spesies non-target (Davies et al., 2009).

Banyak alasan bagi nelayan untuk membuang hasil tangkapan sampingan (spesiesnontarget) (Cabral et al., 2003). Umumnya, pengambilan keputusan didorong oleh faktor ekonomi (Alverson et al., 1994). Biasanya, nelayan akan memilih untuk mempertahankan spesies nontarget yang masih dapat dimanfaatkan, atau spesies yang memiliki nilai ekonomis, namun ketika spesies non-target yang diperoleh hanya satu atau beberapa individu, mereka akan menyimpannya untuk konsumsi sendiri, karena nilai jual yang rendah (Batista et al., 2009; Goncalves et al., 2007). Praktik 
serupa, berdasarkan pengamatan langsung, juga diamati dilokasi penelitian.

Salah satu strategi pengelolaan dari penelitian ini yaitu dengan memperhatikan penggunaan alat tangkap dengan ukuran matajaring (mesh size) yang dominan di gunakan, yakni 3,0-3.5 inci. Apabila penggunaan alat tangkap yang dominan dengan ukuran mata jarring lebih besar atau sama dengan 4 inci, sehingga dengan ini diharapakan spesies non-target yang tertangkap dapat berkurang. Manfaat adanya upaya pengurangan dan pengelolaan hasil tangkapan sampingan (spesies non-target) diantaranya yaitu menjaga spesies di dalam jaring makanan laut alami serta perlindungan terhadap spesies yang terancam punah dan rentan. Selain itu, pengelolaan hasil tangkapan sampingan (spesies non-target) diharapkan dapat menjaga keberlanjutan dan keragaman biota laut. Hal ini juga diharapkan dapat mengurangi limbah di perairan karena aktivitas nelayan dalam membuang spesies non-ekonomis ke perairan menyebabkan spesies-spesies tersebut nantinya terakumulasi dalam jumlah tinggi di perairan, sehingga akhirnya menjadi limbah di perairan.

\section{Kesimpulan}

Keragaman sumberdaya ikan spesies nontarget rajungan di daerah penangkapan (fishing ground) yang berbeda di sekitar Labuhan Maringgai dan Kuala Penet mempunyai keragaman yang tidak jauh berbeda dengan spesies yang ditemukan hampir sama. Proporsi bobot spesies ikan non-target terhadap rajungan di Labuhan Maringgai sedikit lebih tinggi dibandingkan Kuala Penet.

\section{Ucapan Terima kasih}

Penulis sangat berterima kasih kepada pembimbing karena telah diizinkan untuk melakukan studi bergabung dengan BOPTN di Lampung Timur, kontrak penelitian (SPK No. 1346/IT3.11/PN/2017 tertanggal 21 April 2017).
Terima kasih juga kepada nelayan yang telah mengizinkan penulis untuk mengamati dan mengukur sampel rajungan dan non-target selama penelitian. Terakhir kepada seluruh tim untuk dukungan dan bantuannya selama penelitian di lapangan.

\section{Daftar Pustaka}

Alverson, D.L., Freeberg, M.G., Murawski, S.A. \& Pope, J.G. (1994). A global assessment of fisheries bycatch and discards. FAO Fisheries Technical Paper No.339, Rome, $233 \mathrm{pp}$.

Batista, M.I., Celia, M.T. \& Henrique, N.C. (2009). Catches of target species and bycatches of an artisanal fishery: The case study of a trammel net fishery in the Portuguese Coast. Fisheries Research 100: 167-177. doi:10.1016/j.fishres.2009.07.007.

Cabral, H., Duque, J. \& Costa, M.J. (2003). Discards of the beach seine fishery in the central coast of Portugal. Fisheries Research 63: 63-71. doi:10.1016/S01657836(03)00004-3.

Davies, R.W.D., Cripps, S.J., Nickson, A. \& Porter, G. (2009). Defining and estimating global marine fisheries bycatch. Marine Policy (2009). doi:10.1016/j.marpol.2009.01.003. http://www.sciencedirect.com/science/jour nal/0308597X.

European Commission (2002). Communication from the Commission to the Council and the European Parliament on a Community Action Plan to reduce discards of fish. $\operatorname{COM}(2002) 656$ final.

Favaro, B., Rutherfordb, D.T., Duffc, S.D. \& Côté, I.M. (2009). Bycatch of rockfish and other species in British Columbia spot prawn traps: Preliminary assessment using research traps. Fisheries Research 102: 199-206. doi:10.1016/j.fishres.2009.11.013.

Fazrul, H., Hajisamae, S., Ikhwanuddin, M. \& Pradit, S. (2015). Assessing impact of crab gill net fishery to bycatch population in the 
Lower Gulf of Thailand. Turkish Journal of Fisheries and Aquatic Sciences 15: 761771. doi: 10.4194/1303-2712-v15_3_21.

Goncalves, J.M.S., Stergiou, K.I., Hernando, J.A., Puent, E., Moutopoulos, D.K., Arregi, L., Soriguer, M.C., Vilas, C., Coelho, R. \& Erzini, K. (2007). Discards from experimental trammel nets in southern European small-scale fisheries. Fisheries Research 88: 5-14. doi:10.1016/j.fishres.2007.06.017.

Iskandar, D. (2010). Comparison of shrimp catches using lapdu, giltong and trammel net in Waters of Saengga of Bintuni Bay Regency. Jurnal saintek perikanan 5(2): 80-87.

Kelleher, K. (2005). Discards in the World's Marine Fisheries An Update. FAO Fisheries Technical Paper 470, FAO Rome. 131 pp.

Leland, J., Butcher, P., Broadhurst, M.K. \& Paterson, B.D. (2013). Relative trap efficiency for recreationally caught eastern Australia blue swimmer crab (Portunus pelagicus) and associated injury and mortality discard. Fisheries Research 147: 304-311.

Read, A.J. (2013). Development of conservation strategies used to mitigate the bycatch of harbor porpoises in the Gulf of Maine. Endangered Species Research 20: 235-250.

Reeves, R.R., McClellan, K. \& Warner, T.B. (2013). Marine mammal bycatch and other entangling net fisheries, 1990 to 2011. Endangered Species Research 20: 71-97.

Wardiatno, Y. \& Zairion. (2011). Study on bioecology of the blue swimming crab and bioeconomic performance of crab fishery in order to propose of spawning ground protection. Bogor, Indonesia: Indonesian Blue Swimming Crab Processing Association (APRI) in cooperation with Department of Aquatic Resources Management (ARM-FFMS-IPB): 77p.

Zairion; Wardiatno, Y., Fahrudin, A., \& Mennofatria, B. (2014). Spatial temporal distribution of Portunus pelagicus (Portunus pelagicus) breeding population in coastal waters of East Lampung. Bawal $6(2): 95-102$.

Zairion. (2015). Pengelolaan Berkelanjutan Perikanan Rajungan (Portunus pelagicus) di Lampung Timur, disertasi. Program Pasca Sarjana, Institut Pertanian Bogor, Bogor. 
Tabel 2. Komposisi spesies non-target ikan di Pesisir Lampung Timur ( $\mathrm{D}=$ discarded $; \mathrm{R}=$ retained species)

\begin{tabular}{|c|c|c|c|c|c|c|c|}
\hline Labuan Maringgai & & & & Kuala Penet & & & \\
\hline Spesies & Common name & $\%$ & Status & Spesies & Common name & $\%$ & Status \\
\hline Cynoglossus bilineatus & Fourlined tonguesole & 1,45 & $\mathrm{R}$ & Cynoglossus bilineatus & Fourlined tonguesole & 0,51 & $\mathrm{R}$ \\
\hline Brevytrigon walga & Scaly whipray & 0,38 & $\mathrm{R}$ & Brevytrigon walga & Scaly whipray & 0,61 & $\mathrm{R}$ \\
\hline Platycephalus indicus & Bartail flathead & 0,55 & $\mathrm{R}$ & Platycephalus indicus & Bartail flathead & 0,62 & $\mathrm{R}$ \\
\hline Plotosus canius & Gray eel-catfish & 2,34 & $\mathrm{R}$ & Plotosus canius & Gray eel-catfish & 1,47 & $\mathrm{R}$ \\
\hline Johnius amblycephalus & Bearded croaker & 2,06 & $\mathrm{R}$ & Johnius amblycephalus & Bearded croaker & 1,38 & $\mathrm{R}$ \\
\hline Epinephelus diacanthus & Spinycheek grouper & 0,10 & $\mathrm{R}$ & Panna microdon & Panna croaker & 0,81 & $\mathrm{R}$ \\
\hline Panna microdon & Panna croaker & 0,77 & $\mathrm{R}$ & Sillago sihama & Silver sillago & 0,29 & $\mathrm{R}$ \\
\hline Sillago sihama & Silver sillago & 0,14 & $\mathrm{R}$ & Pomadasys kaakan & Javelin grunter & 0,05 & $\mathrm{R}$ \\
\hline Pomadasys kaakan & Javelin grunter & 0,04 & $\mathrm{R}$ & Eleutheronema tetradactylum & Fourfinger threadfin & 1,34 & $\mathrm{R}$ \\
\hline Eleutheronema tetradactylum & Fourfinger threadfin & 1,58 & $\mathrm{R}$ & Psettodes erumei & Indian halibut & 1,08 & $\mathrm{R}$ \\
\hline Triacanthus nieuhofi & Silver tripodfish & 0,80 & $\mathrm{R}$ & Cynoglossus lingua & Long tongue sole & 0,10 & $\mathrm{R}$ \\
\hline Psettodes erumei & Indian halibut & 0,44 & $\mathrm{R}$ & Maculabatis gerrardi & Sharpnose stingray & 0,28 & $\mathrm{R}$ \\
\hline Maculabatis gerrardi & Sharpnose stingray & 0,50 & $\mathrm{R}$ & Diagramma pictum & Painted sweetlips & 0,20 & $\mathrm{R}$ \\
\hline Diagramma pictum & Painted sweetlips & 0,19 & $\mathrm{R}$ & Nemipterus furcosus & $\begin{array}{l}\text { Fork-tailed threadfin } \\
\text { bream }\end{array}$ & 0,03 & $\mathrm{R}$ \\
\hline Nemipterus furcosus & $\begin{array}{l}\text { Fork-tailed threadfin } \\
\text { bream }\end{array}$ & 0,06 & $\mathrm{R}$ & Chiloscyllium punctatum & $\begin{array}{l}\text { Brownbanded } \\
\text { bambooshark }\end{array}$ & 0,28 & $\mathrm{D}$ \\
\hline Upeneus sundaicus & Ochrebanded goatfish & 0,03 & $\mathrm{D}$ & Platax teira & Longfin batfish & 0,08 & $\mathrm{D}$ \\
\hline Lactoria cornuta & Longhorn cowfish & 0,24 & $\mathrm{D}$ & Ephippus orbis & Orbfish & 0,25 & $\mathrm{D}$ \\
\hline Halophryne diemensis & Banded frogfish & 0,18 & $\mathrm{D}$ & Halophryne diemensis & Banded frogfish & 0,27 & $\mathrm{D}$ \\
\hline Sardinella gibbosa & Goldstripe sardinella & 0,02 & $\mathrm{D}$ & Scatophagus argus & Spotted scat & 0,22 & $\mathrm{D}$ \\
\hline Selaroides leptolepis & Yellowstripe scad & 0,16 & $\mathrm{D}$ & Terapon theraps & Largescaled terapon & 0,06 & $\mathrm{D}$ \\
\hline Scatophagus argus & Spotted scat & 0,25 & $\mathrm{D}$ & Selaroides leptolepis & Yellowstripe scad & 0,12 & $\mathrm{D}$ \\
\hline
\end{tabular}


Zairion et al., Jurnal Bologi Tropis, 19 (1) : $8-13$
DOI: http://dx.doi.org/10.29303/jbt.v19i1.942 